\title{
POTENTIAL MINIMUM COST OF ELECTRICITY OF SUPERCONDUCTING COIL TOKAMAK POWER REACTORS*
}

\author{
R. L. Reid and Y-K. M. Peng \\ Oak Ridge National Labaratory, P. O. Box 2009, Oak Ridge, Tennessee 37831-8218
}

\section{ABSTRACT}

The potential minimum cost of electricity (CO for superconducting tolamak power reactors is estimated by increasing the phyaica (confinement, beta limit, bootstrap current fraction) and technology (neutral beam energy, toroidal field (TF) coil allowable stresses, divertor heat flux, superconducting coil critical field, critical temperature, and quench temperature rise] constraints far beyond those assumed for ITER until the point of diminishing returas is reached. A version of the TETRA systems code, calibrated with the ITER design and modified for power reactors, is used for this analysis, limiting this study to reactors with the same basic device configuration and coating algorithms as ITER. A minimum COE is reduced from $>200$ to about 80 mill/ $\mathbf{k W h}$ when the allowable design constraints are raised to 2 times those of ITER. At 4 times the ITER allowables, a minimum COE of about $60 \mathrm{mill} / \mathrm{kWh}$ is obtained. The corresponding tokamak has a major radius of approximately $4 \mathrm{~m}$, a plasma current close to $10 \mathrm{MA}$, an aspect ratio of 4 , a confinement H-factor $\leq 3$, a beta limit of approximately 2 times the first stability regime, a divertor heat flux of about 20 $\mathrm{MW} / \mathrm{m}^{2}$, a $B_{\max } \leq 18 \mathrm{~T}$, and a TF coil average current density about 3 times that of ITER. The design constreinis that bound the minimum COE are the allowable stresses in the TF coil, the neutral beam energy, and the $99 \%$ bootatrap current (ewentially free current drive).

\section{INTRODUCTION}

This study is motivated by the following reasons:

1. Recent studies of commercial reactor concepts assume varied advances in physics and technology, which lead to a wide range of COE estimatea. To assess the importance of rarious scientific and technical advances in reducing COE, COE minimisation is syatematically approached ${ }^{1}$ vis constrained variation of major design variables.

2. Recent studies of ITER-like reactors ${ }^{2}$ and advancedtechnology future reactors [i.e., ARIES-1 (Ref. 3)] have shown interesting correlations between COE and design assumptions. This study aims to clarify the needed advances in physics and technology beyond ITER to attain the ultimate potential minimum COE for the superconducting tokamak reactors, for which ITER aspires to be the first experimental reactor.

This study of tolamak power reactors, then, (1) determines the minimum COE and design parameters for reactors consistent with present ITER physics, technology, and engineering constraints and (2) determines the limiting COE as the constraints are systematically relaxed up to a point of diminishing returns. In each part of the study, the physics and engineering parimeters consistert with the minimum COE are found subject to the imposed conatraints of divertor heat flux, maximum TF, beta limit, confinement time, beam energy, magnet stress, superconducting magnet critical field and tempereture, etc. Critical trade-offis in key desiga issues, such aspect ratio, maximum TF, and confinement scaling, are aloo clarified for reactors.

This paper addresses (1) modifications to the TETRA code 1 in order to model power reactors, (2) benchmarking the technology phese of the ITER design with the modified code (called TETRA-R), (3) benchmarking two previous power reactor studies (GENEROMAK, TPSS ${ }^{5}$ ) with the TETRA-R code, and (4) determining the minimum COE as a function of the degree of relaxetion of the ITER limita and conatraints. The paper ends with conclusions and discussions.

\section{CODE MODIFICATIONS}

The TETRA code was written specifically to model an experimental power reactor. The thermal power was dumped to the atmosphere by way of a cooling tower, and no provision was made in the code for specifying the use of a turbine generator. In order to complete this study, TETRA was modified to include models of power blankets; turbine generatora; an economics package to compute COE; adjustments of unit costs assuming a mature reactor economy; and treating replaceable tokmak components (e.g. blanket and divertor) as recurring costs similar to fuel costs in a fission reactor. ${ }^{4}$ In addition, the code was upgraded with a recent fired boundary MHD equilibria package so as to more accurately model the poloidal field (PF) system ${ }^{\circ}$ and to provide for consistency between the value of bets used

*Research sponsored by the Office of Fusion Energy, U.S. Department of Energy, under contract DE-ACo5-84OR21400 with Martin Murietta Energy Syatems, Ine. 


\section{DISCLAIMER}

This report was prepared as an account of work sponsored by an agency of the United States Government. Neither the United States Government nor any agency thereof, nor any of their employees, makes any warranty, express or implied, or assumes any legal liability or responsibility for the accuracy, completeness, or usefulness of any information, apfaratus, product, or process disclosed, or represents that its use would not infringe privately owned rights. Reference herein to any specific commercial product, process, or service by trade name, trademark, manufacturer, or otherwise does not necessarily constitute or imply its endorsement, recommendation, or favoring by the United States Government or any agency thereof. The views and opinions of authors expresser herein do not necessarily state or reflect those of the United States Government or any agency thereof. 
in the power balance and the value of beta used in the plasma equilibrium determination.

\section{Blanket}

The blanket model supplies a consistent set of input parameters based on blanket materials and temperatures desired. These parameters are taken from previous detailed analysis of candidate blanket configurations such as those presented in Ref. 7. These include inboard thickness, outboard thickness, average density consistent with volume fractions of materials used, average unit cost, energy multiplication factor, and thermal conversion efficiency.

\section{Capital costs}

The capital cost computations in the TETRA code are modified for power reactor application. The elements of the tokamak are conted based on ITER unit cost and modified for learning curve effects, and the costs of the balance of plant (BOP) and heat transport systems are scaled finctions of thermal or electrical power as suggeated in Ref. 4 and updated according to Ref. 8. Building coats are modified to include the cost of a turbine building. The costs of the first wall, blenket, divertor, and $25 \%$ of the current drive system are treated as recurring costs (similar to fuel costs in a fisaion reactor) and are, therefore, not included in the total capital cost. Indirect costs and interest during const:uction are accounted for.

As previously indicated, the unit coats for developmental portions of the reactor are corrected consistent with a mature reactor economy (tenth-of-a-kind) based on the cost data base accumulated at the Fusion Engineering Design Center. ${ }^{0,10}$ Representative values used in the systems code for ITER and for s reactor version of ITER are shown in Table $I$.

\section{Economics model}

A package to compute the COE, similar to that found in Ref. 4 and updated according to Ref. 11, was added to the aystems code. The capital inveatment computed in the code is converted to an annual cost based on an input constant-dollar fixed charge rate (which is a function of plant life, interest rate, inflation rate, tax rate, etc.).

The net electric power, used in computing the COE, is baged on converting the available thermal power to electric power using an input thermal conversion efficiency and subtracting the current drive power and BOP recirculating power.

The costs of the replaceable components, such as the blanket and divertor, are treated as fuel-type charges
Table I. Unit cont for tokmak syatems

\begin{tabular}{|c|c|c|}
\hline & $\begin{array}{r}\text { ITER } \\
\text { bese }\end{array}$ & $\begin{array}{c}\text { Reactor } \\
\text { bese }\end{array}$ \\
\hline \multicolumn{3}{|l|}{ Fint wall $\left(9 / \mathrm{m}^{2}\right)$} \\
\hline Inboard & 166,000 & 60,000 \\
\hline Outboard & 61,000 & 60,000 \\
\hline Divertor $\left(\$ / \mathrm{m}^{2}\right)$ & 700,000 & 100,000 \\
\hline \multicolumn{3}{|l|}{ Blenket (\$/kg) } \\
\hline Steal & & 50 \\
\hline Vanedium & & 400 \\
\hline Lithium & & 45 \\
\hline Shield (ateel)(\$/kg) & 28 & 28 \\
\hline \multicolumn{3}{|l|}{ Megnet: } \\
\hline \multicolumn{3}{|l|}{ TF coils OH solenoid $\left(\$ / \mathbf{k g}_{\mathrm{B}}\right)$} \\
\hline NbsSn wire & $(650-600) z^{a}$ & $900-350) x$ \\
\hline Case & 80 & 50 \\
\hline Winding process & 130 & 50 \\
\hline $\begin{array}{l}\text { EP coilu }(\$ / \mathbf{L A} \cdot \mathrm{mT}) \\
\text { NbaSn conductor }\end{array}$ & $\mathbf{2 . 3}$ & 1.8 \\
\hline
\end{tabular}

and are amortized over the lives of these components. The blanket life is based on the neutron wall loading, an input material fluence limitation, and the plant capacity factor. The divertor life is based on a limiting divertor heat flux, a divertor material fluence limitation, and the plant capacity factor. A peaking factor (peak-to-average divertor heat flux) is also input to the code. The divertor plate angle is optimised based on hest flux and vertical build considerations.

\section{BENCHMARK TO ITER}

The TETRA-R code is used to simulate the currentdriven, steady-atate (major radius of $5.5 \mathrm{~m}$, plasma current of $18 \mathrm{MA}$ ) version of ITER. Global parameters for this device are shown in Table II. Table III gives the

Table II. TETRA-R code aimulation of ITER global parameter.

\begin{tabular}{ll}
\hline Major radius, m & 5.50 \\
Aspect ratio & 3.06 \\
Neutron wall load, MW/m & 1.02 \\
Plasma current, MA & 18 \\
Plasms temperature, l:eV & 17.6 \\
Maximum toroidal field, T & 11.7 \\
Current drive power, MW & 114 \\
Bootstrap current fraction & 0.28 \\
Bets, \% & 5.7 \\
Divertor heat flux, MW/m & 10 \\
Neutral beam energy, keV & 1000.0 \\
Current drive efficiency & \\
Neutral beam & 0.11 \\
Lower hybrid & 0.11 \\
\hline
\end{tabular}


Table III. Capital cost for ITFR configuration and a reactor based on ITER

\begin{tabular}{lrr}
\hline & \multicolumn{2}{c}{ Cost (millions of dollars) } \\
\cline { 2 - 3 } & ITER & Reactor \\
\hline Buildings & 254 & 280 \\
First wall & 69 & 40 \\
Blanket and shield & 398 & 398 \\
Structure & 86 & 86 \\
Divertor & 90 & 13 \\
TF magnets & 500 & 291 \\
PF magnets & 304 & 146 \\
Cryostat & 17 & 17 \\
Current drive system & 379 & 379 \\
Vacuum system & 61 & 15 \\
Power conditioning & 147 & 147 \\
Heat transport & 104 & 94 \\
Fuel handling & 116 & 116 \\
I C C & 100 & 21 \\
Maintenance equipment & 60 & 35 \\
Turbine plant & 0 & 75 \\
Electrical plant & 28 & 68 \\
Misc. plant equipment & 25 & 22 \\
Heat rejection & 30 & 25 \\
Plant direct cost & 2768 & 2268 \\
Process contingency & 487 & 0 \\
Indirect cost & 1139 & 850 \\
Project contingency & 439 & 468 \\
lnterest during & & \\
construction & 0 & 623 \\
Total inveatment & 4833 & 4209 \\
\hline
\end{tabular}

ITER unit cost values and the unit cost values modified for power reactor application. For this comparison, the first wall, blanket, divertor, and all the current drive system costs are included as capital costs, instead of being treated as recurring costs (as in the reactor study). In addition, the water-cooled blanket for ITER is treated as a shield for this comparison.

The direct capital cost for ITER is $\$ 500$ million lower when the reactor costing methodology is used; the difference is in the lower toksmak cost (torus, magnets, etc.), higher building cost because of the turbine building, cost of a turbine-generator, and reduced cost of maintenance equipment, I\&C equipment, etc., assuining a mature reactor economy as opposed to using development equipinent. The total capital investment for ITER is $\$ 600$ million lower for reactor costing than for experimental costing. Going from direct capital cost to total capital iuvestment, the reactor costing methodology has no process contingency and has a lower indirect cost percentage but is required to account for interest during construction. The COE in the reactor study is based on the total capital investment, including the interest during construction.

\section{BENCHMARK TO GENEROMAK AND TPSS STUDIES}

As part of this study, the TETRA-R code was used to simulate the conisguration and performance for pover reactors from previous studies to determine the values of design constraints (such as allowed stress in the magnets) required in these designs relative to the ITER values. Cost values for these power reactors were also estimated with the TETRA- $\mathrm{R}$ code by applying the unit cost values for ITER.

\section{Generomak}

The various elements of the radial build and performance parameters for GENEROMAK are taken from Ref. 4. The aimulation indicated that the GENEROMAK bets limit must be a factor of 1.76 , the divertor heat flux a factor of 2.0 , and the TF coil stress a factor of 1.45 of the ITER limits and constraints. The TETRA-R code gives an estimated COE of 85 mill/kWh, as opposed to the GENEROMAK published value of $53 \mathrm{mill} / \mathrm{kWh}$. Most of the difference lies in the cost of the reactor plant equipment.

\section{TPSS}

The performance values and radial build for the TPSS study were taken from Ref. 5. TPSS is characterised as a low-current, high-beta (second stability) tokamak. Accordingly, the simulation shows that the bets limit must be a factor of 8.6 and the divertor heat flux a factor of 1.33 of the ITER limits and constraints. Also, the TPSS confinement enhancement (H-factor) is 5 as opposed to an ITER value of 1.7. The TETRA-R code gives an estimated COE of 87 mill/kWh as opposed to the T'PSS published value of $32 \mathrm{mill} / \mathrm{kWh}$ (the TPSS published cost is in 1986 constant dollars).

\section{POWER REACTOR PARAMETERS AND COST STUDY}

The objective of this study was to determine reactor parameters consiatent with a minimum COE for tokamak power reactors. The optimizer feature of the TETRA-R code was used to find the minimum COE with the constrained optimization process described in Ref. 1. The minimum COE was determined for power resctor configurations sized at ITER limits; at 1.5 times ITER limits; at 2 times ITER limits; at 3 times ITER limits; and at 4 times ITER limits. The base ITER limits are shown in Table IV. Note that for 2 times the ITER limits, it is implied that the TF stress limit is raised by factor of 2 (from 600 to $1200 \mathrm{MPa}$ ), the 
Table IV. Base ITER limits

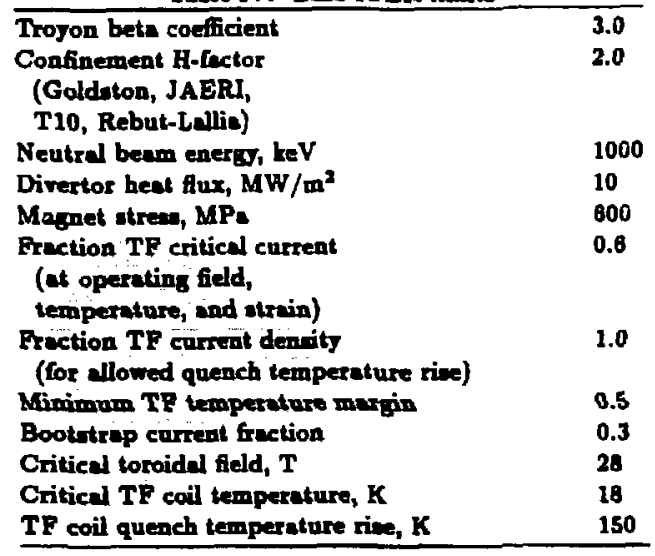

allowable neutral beam energy is increased by a factor of 2 (from 1000 to $2000 \mathrm{keV}$ ), etc. The exception to this procedure is the TF current density, which is taken to be the lowert of the base value of 0.6 times the critical current density at the operating temperature, field, and strain; the current density consistent with - given coil temperature rise during a coil quench; or the current density consistent with a given temparature margin. The fundemental superconducting properties themselves ( $B_{\text {erit }}, T_{\text {exit, }}$ quench temperature rise) are raised by the incremental increase in ITER limits. The bootstrap current is varied from an initial value of 0.3 to a maximum value of 0.99 , and the coil temperature during quench is varied from an initial value of $150 \mathrm{~K}$ to a maximum value of roos temperature as the ITER limits are increased up to a factor of 4.

The net electric power was limited to $1000 \mathrm{MW}$ for this study. It is well known that the COE decreases as the net electric power increases. However, a value of 1000-1300 MW(e) is the power level farored by most electrical utilities. Other fixed parameters are listed in Table V.

Table VI is a concise summary of the results of this study. The minimum COE achievable for each of the five ITER limit multipliers $(1,1.5,2,3$, and 4) is given; these COEs are based on an "F-factor," the ratio of the actual limit to the allowable limit for each constraint. For a power reactor configured at the ITER limits (multiplier of 1), all of the allowable limits are reached except for the confinement H-factor (2.0 allowed, 1.87 selected) and the net electric power $(\mathrm{F}=1.0$ allowed, $\mathbf{F}=\mathbf{0 . 4 8}$ seiected). The divertor hest flux is the primary constraint that keeps the net electric power from reaching the allowable limit of $1000 \mathrm{MW}$ for minimum COE (205 mill/kWh) in this configuration. For a power resctor configured at twice the ITER limits (multiplier of 2), the net electric power, beta, beam energy, TF coil case stresa, divertor heat flux, and bootstrap current fraction all reach the allowable limits, and the
Table V. Pixed parameters for this otudy

\begin{tabular}{|c|c|}
\hline Plande elongetion to $X$-point & 2.278 \\
\hline $\begin{array}{l}\text { Plane afety fector at } 85 \% \text { flux } \\
\text { Blanket }\end{array}$ & 3.1 A \\
\hline Inboerd thicknes, in & 0.6 \\
\hline Outboard thicknen, in & 0.7 \\
\hline $\begin{array}{l}\text { Energy multiplication } \\
\text { Shield }\end{array}$ & 1.27 \\
\hline Inboard thicknese, in & 0.6 \\
\hline Outboard thickneen, m & 1.0 \\
\hline Current drive electrieal eficieney, \% & 75 \\
\hline Thermal efficiency, \% & 40 \\
\hline BOP circulution power, $\%$ & $\theta$ \\
\hline Firnt wall finence, MW-yz/m² & 20 \\
\hline Avalsbility, \% & 75 \\
\hline Plent life, $\mathrm{J}$ & 30 \\
\hline Construction time, yr & 6 \\
\hline Fixed charge rate & 0.0986 \\
\hline Effective cost of mones, \% & 9.57 \\
\hline Infintion rute, \% & $\mathbf{5 . 0}$ \\
\hline Bffective tax rate, $\%$ & 36.6 \\
\hline
\end{tabular}

Table V1. P-fuctore (ratios of actoal limits to allowable limito), H-factor, bootetrap eurrent fraction, and minimum COE for reactors baned on ITER limit multipliers of $1,1.5,2.3$, and 4

\begin{tabular}{|c|c|c|c|c|c|}
\hline & \multicolumn{5}{|c|}{ Limit multiplier } \\
\hline & 1 & 1.5 & 2 & 3 & 4 \\
\hline \multicolumn{6}{|l|}{ F-factor } \\
\hline Net electrical powere & 0.48 & 0.81 & $1.0^{b}$ & 1.0 & 1.0 \\
\hline Beta limit & 1.0 & 1.5 & 2.0 & 2.09 & 1.87 \\
\hline Beam energy & 1.0 & 1.5 & 2.0 & 2.96 & 1.0 \\
\hline Current denity over TP coile & 0.53 & 1.17 & 1.23 & 3.50 & 3.21 \\
\hline TP coil cane itres & 1.0 & 1.8 & 2.0 & 2.68 & 4.0 \\
\hline TF coil atrew & 1.0 & 1.8 & 1.76 & 2.51 & 4.0 \\
\hline Divertor heat flux & 1.0 & 1.8 & 2.0 & 2.02 & 2.02 \\
\hline H-factor & 1.87 & 2.77 & 2.32 & 2.41 & 2.81 \\
\hline Bootstrap current fraction & 0.20 & 0.45 & 0.60 & 0.00 & 0.00 \\
\hline Minimum COE, mill/kWh & 204.8 & 103.7 & 70.1 & 65.0 & 61.4 \\
\hline
\end{tabular}

Limited to $\leq 1000 \mathrm{MW}$.

'Bold ralues are at the ellowable limits.

-Relative to the ITER vilue. The allowable value in determined by raiting the critical field, critical temperature, and temperature during a coil queach from the ITEA ralued (28 T, $18 \mathrm{~K}$, and $150 \mathrm{~K}$ ) by the limit multiplier.

The bare H-factor at the ITER limit is 2.

COE drops to $79 \mathrm{mill} / \mathrm{kWh}$. At the maximum limita addreased in this study (multiplier of 4), the COE is $61 \mathrm{mill} / \mathrm{kWh}$, with the bootstrap current fraction, TF coil stress, beam energy, and net electric power all at their allowable limits. Table VI shows that the confinement $\mathrm{H}$-factor need not be greater than 3 and that the beta limit and the divertor heat flux limit need not be greater than a fastor of about 2.0. The major reduction in COE, as seen from Table VI and Fig. 1, occurs when the ITER limits are multiplied by 2.

The COE, as shown in Fig. 1, is composed of three elements: the capital investment (by far the greatest contributor), operating and maintenance costs (O\&M), and the costs of the replacesble components, such as blankets and divertor, which are similar to fuel chargea in fission plants. The O\&M costs are scaled as a function of power level. The fuel-type costs are determined 


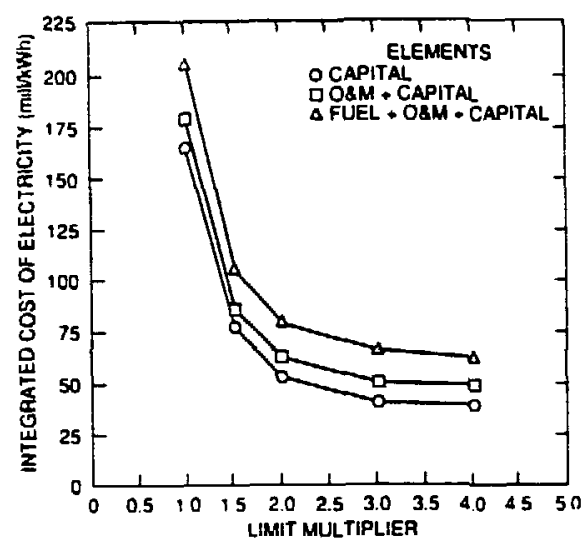

Fig. 1. COE rs limit multiplier.

as a function of the initial coats of the blanket and divertor and a portion of the current drive system cost and amplified by the number of replacements over the plant life, which variea inversely with neutron wall loading. The direct capital cost portion of the COE is show $n$ in Fig. 2 as a function of the limit multiplier. The mejor reduction in capital cost is associated with the cost of the nuclear island (shield, structure, TF and PF magnets, cryostat, and current drive system). The cost of the BOP, buildinge, and other reactor plant equipment is relatively insensitive to variation in the constraint multiplier.

Global parameters of interest for this study are presented in Table VII. For the limit multipliers used, the major radius decreases from 7.51 to $3.97 \mathrm{~m}$, the net electric powrer increases from 481 to the maximum value of $1000 \mathrm{MW}$, the plasma current decreases from 19.7 to 9.2 MA, and the neutron wall load increases from 0.99 to $6.44 \mathrm{MW} / \mathrm{m}^{2}$ with an accompanying decrease in blanket life from 27 to 4.1 years. The current drive power decreases from 128 to $4.8 \mathrm{MW}$ because of the allowable increase in the boototrap current fraction from 0.3 to 0.99 . The required H-factor for confinement in-

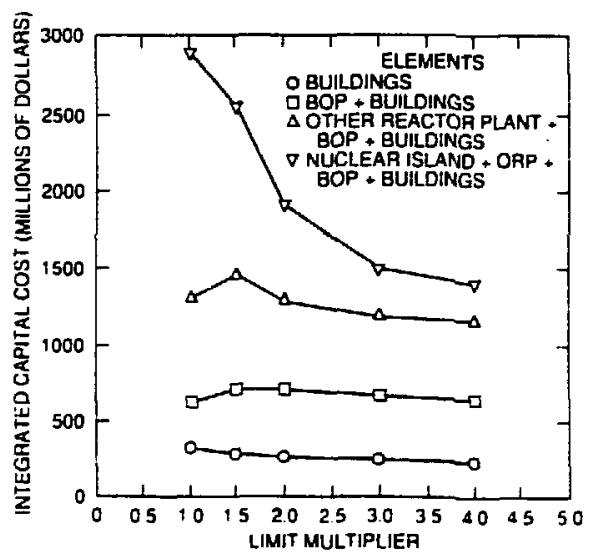

Fig. 2. Direct capital cost $\mathrm{v} s$ limit multiplier. creases from 1.87 to 2.81 . The maximum toroidal field increases from 11 to $17 \mathrm{~T}$; however, very broad minima exist as a function of maximum field for each constraint multiplier, as shown in Fig. 3. Aspect ratio, over the range of this study, varied from about 3 to 4 for minimum COE. Further increases in aspect ratio would result in a higher COE, as shown in Fig. 4.

Table VII. Reaclor paraneter

\begin{tabular}{|c|c|c|c|c|c|}
\hline & \multicolumn{5}{|c|}{ Limil multipliex } \\
\hline & 1 & 1.5 & 2 & 3 & 4 \\
\hline Major radius, m & 7.51 & 6.70 & 5.11 & 4.20 & 3.97 \\
\hline Aspect ratio & 3.54 & 3.83 & 3.21 & 3.62 & 4.08 \\
\hline ic power, MW & 481 & 810 & 1000 & 1000 & 1000 \\
\hline Plasm & 19.7 & 18.6 & 15.6 & 11.1 & 0.2 \\
\hline Bets & 0.047 & 0.058 & 0.106 & 0.097 & 0.076 \\
\hline$r_{\text {n, heV }}$ & 21.0 & 27.0 & 20.6 & 13.6 & 8.4 \\
\hline Musion power, MW & 1321 & 2190 & 2327 & 2231 & 2107 \\
\hline $\begin{array}{l}\text { Neutron wall loed, } \\
\mathbf{M W} / \mathbf{m}^{\mathbf{2}}\end{array}$ & 0.89 & 2.24 & 3.30 & 5.00 & 6.44 \\
\hline Blanket life, yr & 27.0 & 12.0 & 7.8 & 5.2 & 4.1 \\
\hline ment H-fuctor & 1.87 & 2.77 & 2.32 & 2.41 & 2.81 \\
\hline $\begin{array}{l}\text { Current drive } \\
\text { power, MW }\end{array}$ & 128 & 05.2 & 67.0 & 21.0 & 4.7 \\
\hline Boolntrap current frection & 0.3 & 0.45 & 0.60 & 0.00 & 0.90 \\
\hline$B_{\text {maxte }}, \mathbf{T}$ & 11 & 13 & 13 & 15 & 17 \\
\hline$J_{\nabla p}, \mathrm{MA} / \mathbf{m}^{2}$ & 15.3 & 33.8 & 35.8 & 102 & 93 \\
\hline$J_{\text {oed }}, \mathrm{MA} / \mathrm{m}^{3}$ & 9.0 & 17 & 22.6 & 47 & 55 \\
\hline
\end{tabular}

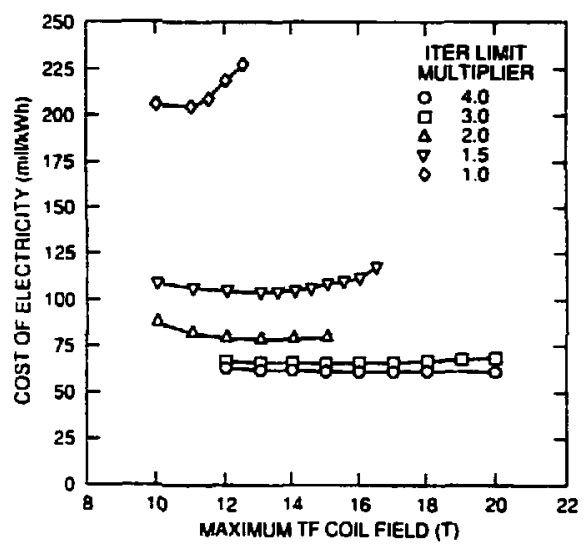

Fig. 3. COE vs maximum TF coil field.

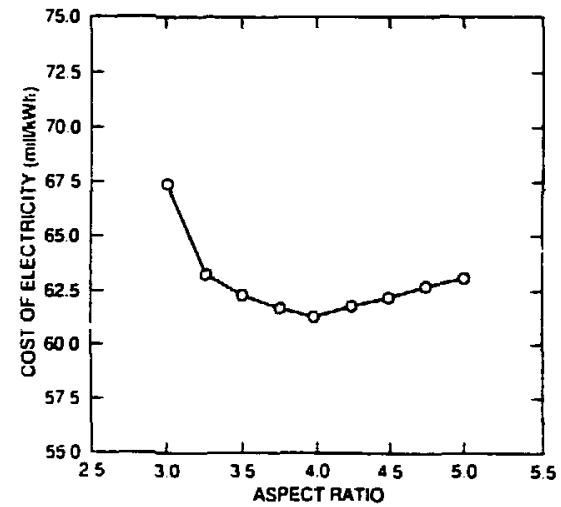

Fig. 4. COE vs aspect ratio for a limit multiplier of 4. 


\section{CONCLUSIONS AND DISCUSSION}

This study assumed constant kappa, safety factor, blanket thickness, shield thickness, gaps, costing algorithms, component deaign models, and net electric power. The following conclusions are drawn.

The potential minimum COE is approximately $60 \mathrm{mill} / \mathrm{kW} / \mathrm{h}$ when the deoign constraints are increased to 4 times the ITER limits. This minimum COE is bounded by the atress in the TF coil, the neutral beam energy, and the $99 \%$ bootstrap current fraction (i.e., easentially free current drive).

The largest decrease in the COE is obtained when the disuign constraints are increased to 2 times those for ITER (from 205 te 79 mill/kWh).

The confinement H-factor need not be $>3$ to achieve this potential minimum COE. This corresponds to the super-H-mode confinement regime (Ref. 12).

The beta limit need not be more than 2 times that for the first stability regime (Ref. 13).

The divertor heat flux need not exceed the present ITER deaign limit by more than a factor of 2 .

The maximum field at the TF coil need not exceed $18 \mathrm{~T}$, despite an asumed critical field of $112 \mathrm{~T}$, a critical temperature of $72 \mathrm{~K}$, and a quench temperature rise of $300 \mathrm{~K}$ for the superconductor in a forced-flow, cable-inconduit design.

The aspect ratio consistent with the minimum COE lies between 3 and 4 for all cases conaidered.

These conclusions are valid subject to the following limitations and uncertainties.

1. The reactor concepts are limited to those with a tokamak power core similar to ITER in configuration, in the basic design of major components, and in the cost estimating approaches of sire, volume, and weight. Breakthroughs in science and technology that fundamentally alter the basis for these assumptions would lead to difierent configurations, component deaigns, and costing approaches that would render our COE reoulte pesaimistic.

2. The unit costs per weight or ares are assumed, in this study, to be independent of the advances in technology as scaled by the F-factors. This renders our COE results potentially optimistic.

3. The approach of constrained minimization of COE and the rather uniform application of advances in key phyaics and technology areas have led to a clarification of the "ultimate" potential minimum COE in this "ITER class" of reactors. The actual advances may well be nonuniform in F-factors used and lead to COEs higher than those indicated here.
The ability of advancement in one ares to substantially reduce $\mathrm{COE}$ depends on the relative advances in several of the other key areas considered here.

A detailed report of the findings in this paper will be provided in a separate article (Ref. 14).

\section{REFERENCES}

1. R. L. Reì, ed., ETR/ITER Systems Code, ORNL/FEDC-87/7, Oak Ridge National Laboratory, April 1988.

2. R. S. Devoto et al., Projections for a Steady-State Tokamak Reactor Based on ITER, UCID-21519, Rev. 1, Lawrence Livermore National Laboratory, July 1989.

3. R. L. Miller et al., "The ARIES-1 High-Field Tokamak Reactor: Deaign Point Determination and Parameter Studies," these proceedings.

4. 1. G. Delene et al, GENEROMAK: Fusicn Physics, Engineering and Costing Model, ORNL/TM10728, Osk Ridge Nationel Leboretory, June 1888.

5. D. Ehat et al., Toleamak Power Systems Studies, FY 1988: A Second Stability Power Reactor, ANL/FPP/86-1, Argonne National Laboratory, March 1987.

6. S. W. Haney, Methodo for the Design and Optimization of Shaped Tokamaks, PFC/RR-88-12, Masaachusetto Institute of Technology, 1888.

7. Blanket Comparison and Selection Study, Final Report, ANL/FPP-84-1, Argonne National Laboratory, 1984.

8. J. G. Delene, Oak Ridge National Laboratory, private communication, February 10, 1989.

9. S. L. Thomson, Fusion Engineering Design Center, "System Code Coat Accounting," private communication, February 1988.

10. S. L. Thomscn, Fusion Engineering Design Center, "Cost Algorithms for Superconducting Magnets," private communication, October 1988.

11. J. G. Delene, Oak Ridge National Laboratory, private communication, February 21, 1989.

12. M. Keilhacker et al., in Proc. 10th Int. Conf. Plasma Physics and Controlled Nuclear Fusion Research, London, October 1984, IAEA, Vienna, 1985, vol. 1, p. 71.

13. F. Troyon et al., Plasma Physics and Controlled Fusion, vol. 26, p. 209, 1984.

14. R. L. Reid and Y-K. M. Peng, "Potential Minimum Cost of Electricity of Superconducting Coil Tokamak Power Reactors," in preparation. 